\begin{tabular}{l} 
2. To: (Receiving Organization) \\
Distribution \\
\hline $\begin{array}{l}\text { 5. Proj./Prog./Dept./Div.: } \\
\text { Solid Waste }\end{array}$
\end{tabular}

8. Originator Remarks:

Approval/Release

11. Receiver Remarks:

$\begin{aligned} & \text { 3. From: (Originating Organization) } \\ & \text { Solid Waste Engineering }\end{aligned}$
$\begin{aligned} & \text { 6. Design Authority/Design Agent/Cog. Engr.: } \\ & \text { DA Pratt }\end{aligned}$

DA Pratt

\author{
4. Related EDT No.: \\ NA \\ 7. Purchase Order No.: \\ NA \\ 9. Equip./Component No.: \\ NA \\ 10. System/Bldg./Facility: \\ 2706-T \\ 12. Major Assm. Dwg. No.: \\ NA
}

13. Permit/Permit Application No.:

NA

14. Required Response Date:

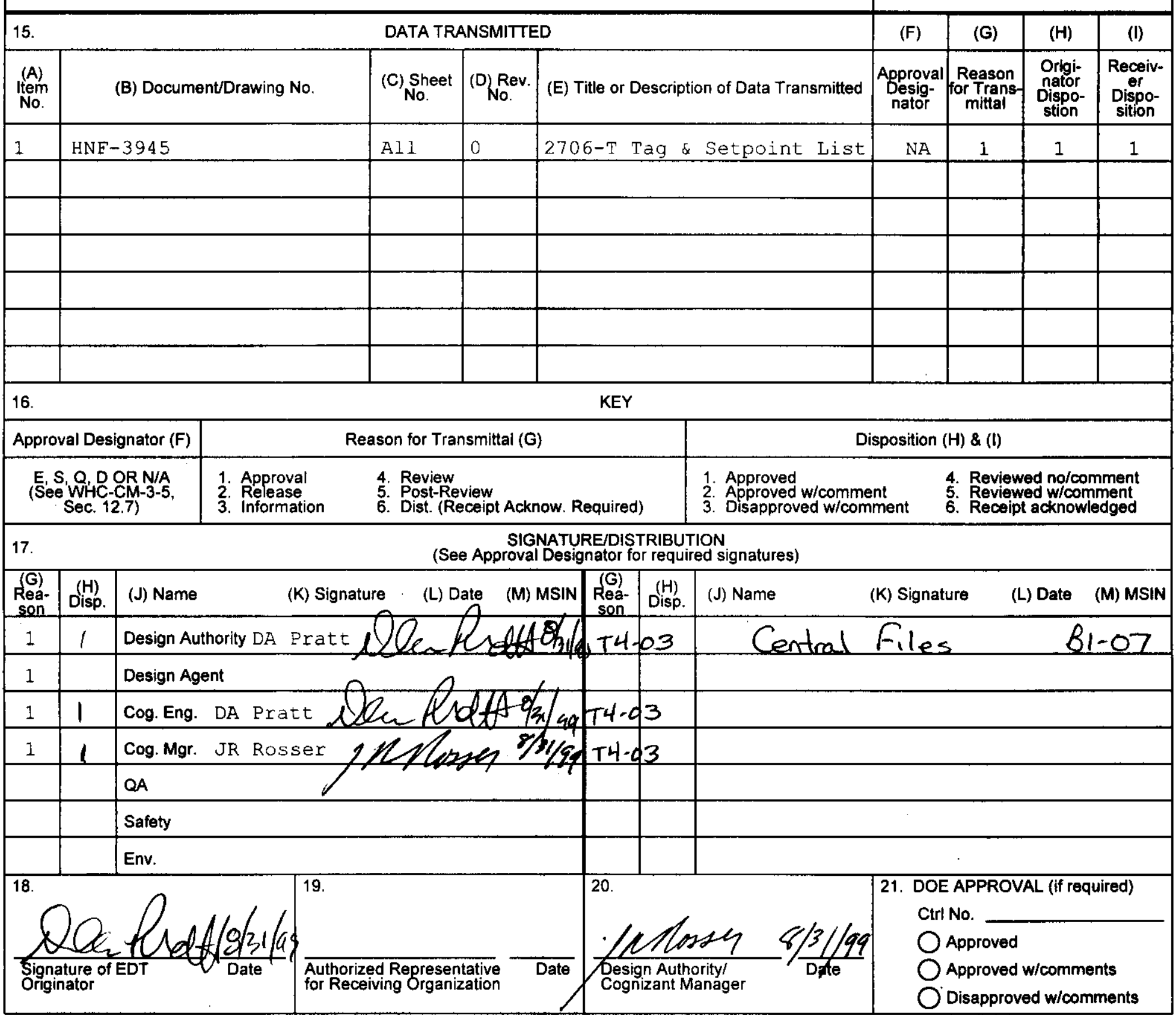




\title{
2706-T Complex Distributed Control System Tag and Setpoint List
}

\author{
D. A. Pratt \\ Waste Management Federal Services of Hanford, Inc. \\ Richland, WA 99352 \\ U.S. Department of Energy Contract DE-AC06-96RL13200 \\ $\begin{array}{ll}\text { EDT/ECN: } & 619473 \\ \text { Org Code: } & 32900 \\ \text { B\&R Code: }\end{array}$ \\ Key Words: Distributed Control System, Taglist, Setpoint, 2706-T \\ UC: \\ Charge Code: 101646 \\ Total Pages: 19
}

\begin{abstract}
:
The 2706-T Distributed Control system (DCS) interfaces with field equipment through analog and digital input and output signals that are terminated at a programmable logic controllex (PLC). The Tag names and addresses of the input and output signals are listed in this document as well as setpoint values assigned to fixed inputs.
\end{abstract}

TRADEMARK DISCLAIMER. Reference herein to any specific commercial product, process, or service by trade name, trademark, manufacturer, or otherwise, does not necessarily constitute or imply its endorsement, recommendation, or favoring by the United States Government or any agency thereof or its contractors or subcontractors.

Printed in the United States of America. To obtain copies of this document, contact: Document Control Services, P.O. Box 950, Mailstop H6-08, Richland WA 99352, Phone (509) 372-2420; Fax (509) 376-4989.

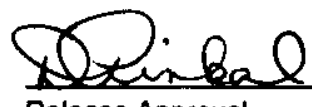

Release Approval

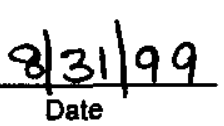

Date

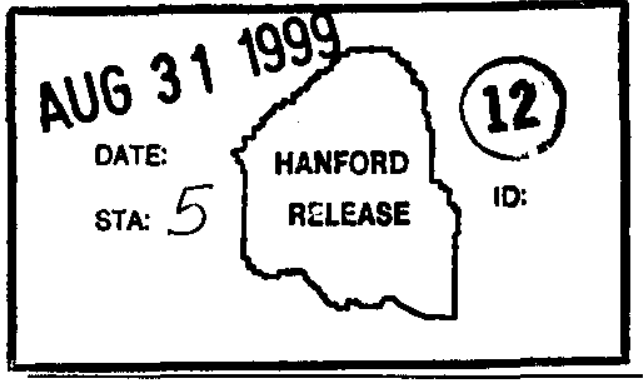

Release Stamp

\section{Approved For Public Release}




\section{CONTENTS}

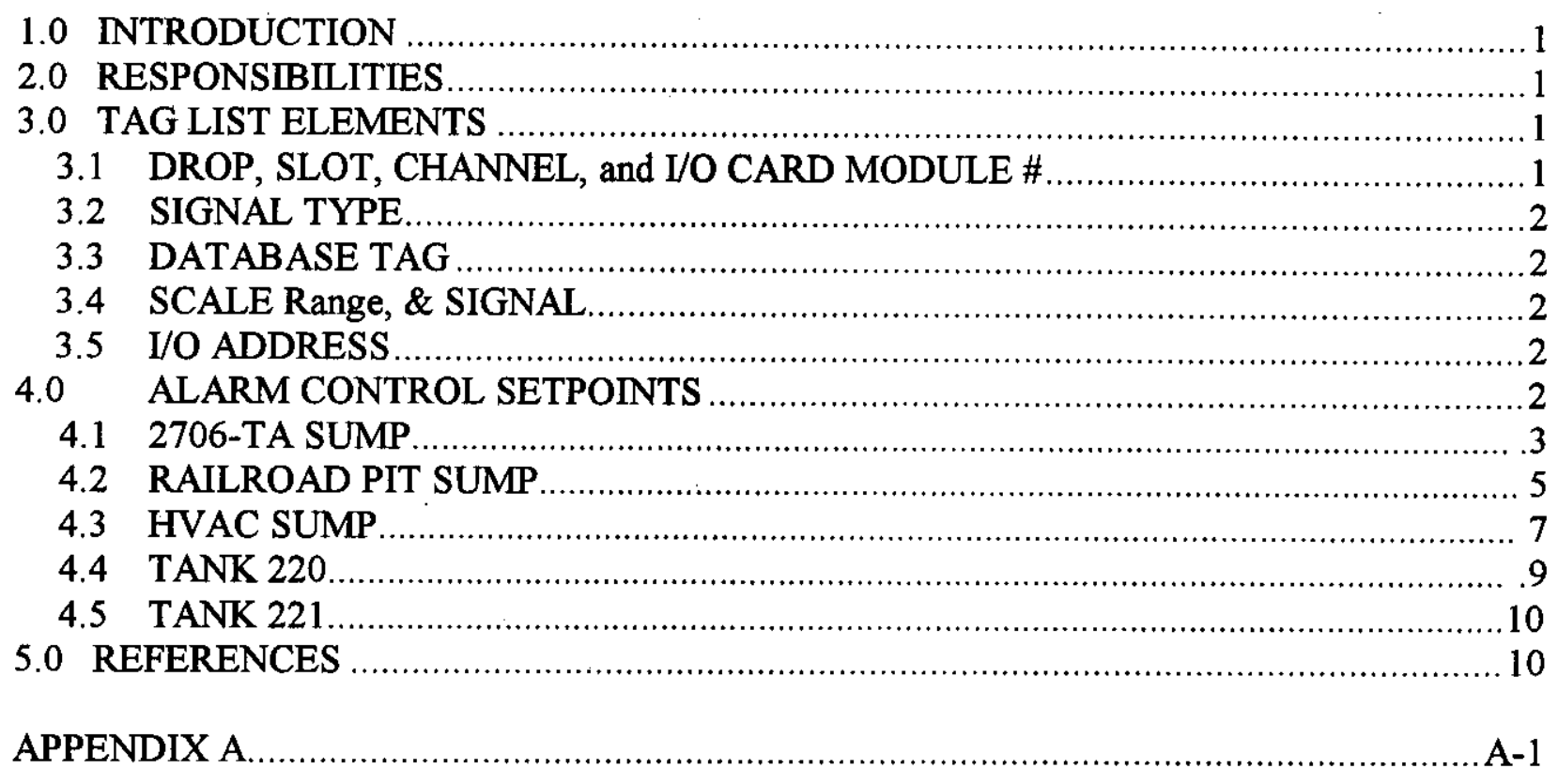




\section{HNF-3945, Rev. 0}

\subsection{INTRODUCTION}

Project W-259 installed a Distributed Control System (DCS) for the 2706-T Complex. The DCS consists of a Modicon ${ }^{\mathrm{TM}}$ (Modicon, Inc.) programmable logic controller (PLC) and several graphic user interface (GUI) stations running Microsoft Windows $\mathrm{NT}^{\mathrm{TM}}$ (Microsoft, Inc.) and Intellutions $^{T \mathrm{M}}$ (Intellutions, Inc.) software. The DCS monitors and controls the related instrumentation and control equipment for the 2706-T Complex. The DCS interfaces with field equipment through analog and digital input and output signals that are terminated at the PLC portion of the DCS. The purpose of this document is to control various hardware and software information for the inputs and outputs to and from the DCS.

\subsection{RESPONSIBILITIES}

This supporting document is a design basis document as defined in the 2706-T Complex Distributed Control System Software Configuration Management Plan (HNF-3940). The computer software elements identified herein shall be changed by an Engineering Change Notice (ECN) in accordance with HNF-PRO-440 (formerly EP-2.2). Engineering is responsible for preparing ECNs and maintaining this Tag and Setpoint List document, which will be revised as necessary.

\subsection{TAG LIST ELEMENTS}

This section provides information regarding the contents of the Tag and Setpoint List. The information in this document is used in one form or another in the applications software for the DCS. Appendix A is a listing of the DCS inputs, outputs, and tags. The following sections refer to the headings in the appendix.

\subsection{DROP, SLOT, CHANNEL, AND I/O CARD MODULE \#}

The DCS has three input/output (I/O) cabinets that contain the various PLC modules (CPU, power supplies, communications, and $\mathrm{I} / \mathrm{O}$ cards). These cabinets are referred to as Drops (DR column in appendix). The physical position of a PLC module in the chassis is called the Slot (SL column in appendix). Field wiring is connected to termination points, called Channels (CH column in appendix), on the individual I/O modules in the PLC cabinets. Software addresses relate the input/output signals to software tags.

The PLC I/O Card Model Numbers for this system include analog input/output (ACI 030), digital input (DAI 553), and digital output (DAO 840, DRC 830). 


\subsection{SIGNAL TYPE}

The Sig Type (signal type) designates the type of tag as being either analog in (AI), analog out (AO), digital in (DI), digital out (DO), calculation (CA), or setpoint (BB).

\subsection{DATABASE TAG}

The software name associated with a particular input, output, or other software parameter is called the Database Tag in the appendix. These tags can represent real field input or output values. They can also be supervisory tags, setpoints, or calculated values that are not directly associated with field signals and thus have no Drop, Slot, or Channel assignment.

\subsection{SCALE/RANGE, AND SIGNAL}

The Scale/Range and Signal columns in the appendix are used to provide signal information for analog and digital signals. For analogs, the Signal column shows the range of the electronic representation (such as 4 to $20 \mathrm{~mA}$ ) of the process variable, and the Scale/Range column shows the corresponding engineering range and units. For example, the 4 to $20 \mathrm{~mA}$ input for LIC-220 is scaled in software from 286 to 15,054 gallons, where $4 \mathrm{~mA}$ represents 286 gallons and $20 \mathrm{~mA}$ represents 15,054 gallons.

For digital signals, the Signal column shows the possible states of a digital input, and the Scale/Range column shows the corresponding status for each state of a digital signal. Basically, the Scale/Range column shows the meaning for each state of a digital input. For example, the possible states for LDA-02 as determined from the Signal column are ON and OFF. From the Scale/Range column for this tag it can be seen that when LDA-02 is ON the status of the leak detector is NORMAL, and when the state is OFF the status of the tag is ALARM. The tag, LDA-02, is an example of a fail-safe alarm configuration.

\subsection{I/O ADDRESS}

This is the PLC address for the inputs and outputs to and from the field equipment.

\subsection{ALARM CONTROL SETPOINTS}

Control Setpoints for alarms in the 2706-T Distributed Control System are set at the computer screen for the 2706-TA sump, the Railroad Pit sump, the HVAC sump, Tank 220, and Tank 221. The recommended set points and a discussion explaining the reasoning behind the selection of each setpoint is given in the following sections. 


\subsection{6-TA SUMP}

The 2706-TA sump has a volume of 524 gallons. At 30 PSI pressure, one pump will drain the sump at a rate of $120 \mathrm{gpm}$. Therefore, the sump will drain in about 5 minutes. The level indicator LIC-03 range is from 5 to 524 gallons. The sump pump starts at high level and shuts off at low-low level. The air sparger starts at high level and shuts off at low level. Alarms occur for sump levels high-high, high, low, and low-low. An alarm is also set for a leak through the sump liner. The alarm setpoint recommendations are given below.

4.1.1 High-high level alarm LAHH-03: Recommended setpoint at 500 gallons. This alarm notifies the operator that the sump is in danger of overflowing. It indicates that:

- $\quad$ The sump pumps are not operating and the railroad pit sump pump(s) are still running. [Unlikely scenario since two separate functions must fail simultaneously. The most likely cause would be if the 2706-TA sump pump control valve(s) were stuck closed and the railroad pit sump pump control valve(s) were stuck open.]

- And/or the fill rate from the railroad pit sump is greater than the discharge rate and the high level alarm interlock to the railroad pits sumps failed. [Unlikely scenario since two separate functions must fail simultaneously. Possible, if both railroad pit sump pumps are running, and the computer failed to receive the high level signal or send the signal to the pump control valve(s).]

4.1.1.1 Recommended alarm response: Push the emergency stop button and stop decontamination activities. Verify that the railroad pit sump pumps have stopped pumping. If they have not, then shut off the air supply to the pumps.

4.1.1.2 Setpoint LAHH_TASUMP: The setpoint limit maximizes the usable space in the sump, and still allows adequate time for operator response to the alarm. The set point is defined by the following criteria:

- $\quad$ Maximize the volume of liquid in the sump before the pump starts, to reduce start/stop cycling of the pump (reduces wear and tear on the machine).

- Allow alarm response time before the sump overflows.

- Maintain separation between pump start and high-high level alarm to allow the pump to prime and get up to speed without activating the high-high level alarm [Avoids false alarms.]

Whereas the sump volume is approximately 524 gallons, and the pump(s) are projected to start at 420 gallons, a setpoint of 500 gallons will satisfy the criteria. 


\section{HNF-3945, Rev. 0}

4.1.2 High level alarm LAH-03: Recommended Setpoint at 420 gallons.

This alarm is very significant in that it is the interlock with the railroad pit sump pumps that fill the 2706-TA sump.

4.1.2.1 Setpoint LAH_TASUMP: The setpoint is defined by the following criteria:

- $\quad$ Maximize the volume of liquid in the sump before the pump starts, to reduce start/stop cycling of the pump. [Reduces wear and tear on the machine.]

- Maintain separation between pump start and high-high level alarm to allow the pump to prime and get up to speed without activating the high-high level alarm. [Avoids false alarms.]

- Maintain enough space between the High and High-high level alarms so that the air sparger will not activate the High-high level alarm when it starts on High level.

- Allow sufficient volume to provide adequate operator response time before the High-high level alarm is activated in the event that the railroad pit sump pump(s) do not shut-off.

Whereas the sump volume is approximately 524 gallons, and the high-high level alarm is set at 500 gallons, starting the pump(s) at 420 gallons will satisfy the criteria.

4.1.2.2 Alarm Response: After a brief interval, verify on the computer screen that the railroad pit sump icons are blue (closed). If so, acknowledge alarm. If not, cut the air supply to the railroad pit sump pumps.

4.1.3 Low-level alarm LAL-03: Recommended setpoint at 60 gallons Low level alarm is a misnomer. It does not indicate an alarm condition. No response is required from the operator other than to acknowledge the alarm. Its function is a part of normal operations in that it stops the air sparger in the automatic mode.

4.1.3.1 Setpoint LAH_TASUMP: The setpoint is defined by the following criteria:

- Liquid covers the air sparger. [The purpose of the air sparger is to mix the liquid. Since it has no function once the liquid level drops below the sparger, it can be turned off.]

- A 60-gallon setpoint shuts off the sparger while it is still covered with liquid, and will satisfy the criteria. The air sparger should start before the sump pump(s) to allow for thorough mixing before pumping. 
4.1.4 Low-low level alarm LALL-03: Recommended setpoint at 2 gallons. Low-low level alarm is a misnomer. It does not indicate an alarm condition. No response is required from the operator other than to acknowledge the alarm. Its function is a part of normal operations in that it shuts off the sump pump(s) in the automatic mode.

4.1.4.1 Setpoint LALL_TASUMP: The setpoint is defined by the following criteria:

- Drain the sump to the maximum extent, but still provide enough residual liquid to maintain pump prime. [Running the pump dry against the head pressure of the residual liquid in the discharge line can compress the air inside the pump to the extent that it loses its suction. Minimizing the dry pump time will help ensure that the pump maintains its prime.]

\subsection{RAILROAD PIT SUMP}

The Railroad pit sump has a volume of 114 gallons. At 30 psi pressure, one pump will drain the sump at a rate of $54 \mathrm{gpm}$. Therefore it takes approximately 2 minutes to drain the sump. The sump level indicator is LIC-02 which ranges from 1 to 106 gallons. The pump starts at high level and shuts off at low-low level. The sparger starts at high level and shuts off at low level. Alarms occur for sump levels high-high, high, low, and low-low. An alarm is also set for a leak through the sump liner. The alarm setpoint recommendations are given below.

\subsubsection{High-high level alarm LAHH-02: Recommended setpoint at 100 gallons.}

This alarm notifies the operator that the sump is in danger of overflowing. It indicates that:

- The sump pump(s) are not operating. [Most probable scenario. Likely causes include Emergency Stop button has not been reset; control valve stuck in the closed position, or diaphragm failure in both pumps.]

- And/or the fill rate from decontamination activities is greater than the discharge rate. [Unlikely scenario. The project W-254 functional design criteria predict fill rates less than $5 \mathrm{gpm}$. Just one of the pumps will pump a minimum of $54 \mathrm{gpm}$.]

\subsubsection{Recommended alarm response:}

4.2.1.2 Sump pump not operating: Typically, the pumps will be running in duplex mode, that is Pump 203 will be pumping with 204 in standby. The operator should look at the computer screen and verify whether the Pump 203 icon on the Railroad Pit Sump A computer screen is blue or white. If it is still blue then the pump did not start. The operator should put the pumps in automatic mode, which will send the signal to start either pump 203 or 204 . If neither pump icon turns white after a brief interval, then the system is disabled and the decontamination activities should be stopped. 


\section{HNF-3945, Rev, 0}

4.2.1.3 Fill rate exceeds discharge rate: Assuming the system is in the duplex mode, the operator should verify that the pump 203 or 204 icon is white [pump running]. If fill rate still exceeds discharge rate, then the decontamination activities should be modified to reduce the fill rate.

4.2.1.4 Urgency of Alarm Response: Response to the high-high level alarm is of relatively low urgency. If the sump overflows, the liquid will still be contained in the railroad pit. Since the pit is designed to accumulate and contain decontamination process fluids, there is minimal concern associated with overflowing the sump. Overflowing the sump would not be considered a spill or release. The relatively small size of the sump reflects the design expectation that liquid volumes greater than the sump volume are an infrequent but expected part of operations.

4.2.1.5 Setpoint LAHH_RRSUMP: The setpoint is defined by the following criteria:

- Maximize the volume of liquid in the sump before the pump starts, to reduce start/stop cycling of the pump. [Reduces wear and tear on the machine.]

- Allow alarm response time while there is a relatively small volume of liquid in the railroad pit containment.

- Maintain separation between pump start and high-high level alarm to allow the pump to prime and get up to speed without activating the high-high level alarm. [Avoids false alarms.]

Whereas the sump volume is approximately 114 gallons, and the pump(s) are projected to start at 80 gallons, a setpoint of 100 gallons will satisfy the criteria.

4.2.2 High level alarm LAH-02: Recommended setpoint at 80 gallons.

High level alarm is a misnomer. It does not indicate an alarm condition. No response is required from the operator other than to acknowledge the alarm. Its function is a part of normal operations in that it starts the air sparger and sump pump(s) in the automatic mode.

4.2.2.1 Setpoint LAH_RRSUMP: The setpoint is defined by the following criteria:

- Maximize the volume of liquid in the sump before the pump starts, to reduce start/stop cycling of the pump. [Reduces wear and tear on the machine.]

- Maintain separation between pump start and high-high level alarm to allow the pump to prime and get up to speed without activating the high-high level alarm. [Avoids false alarms.]

- The difference in alarm levels ensures that agitation of the liquid at high level will not cause a High-high level alarm. 


\section{HNF-3945, Rev. 0}

Whereas the sump volume is approximately 114 gallons, and the high-high level alarm is set at 100 gallons, starting the pump(s) at 80 gallons will satisfy the criteria.

4.2.3 Low-level alarm LAL-02: Recommended setpoint at 40 gallons.

Low level alarm is a misnomer. It does not indicate an alarm condition. No response is required from the operator other than to acknowledge the alarm. Its function is a part of normal operations in that it stops the air sparger in the automatic mode.

4.2.3.1 Setpoint LAL_RRSUMP: The set point is defined by the following criteria:

- Liquid covers the air sparger. [The purpose of the air sparger is mix the liquid. Since it has no function once the liquid level drops below the sparger, it can be turned off.]

A 40 gallon setpoint shuts off the sparger while it is still covered with liquid, and will satisfy the criteria.

4.2.3.2 Discussion: The air sparger should start before the sump pump(s) to allow for thorough mixing before pumping.

4.2.4 Low-low level alarm LALL-02: Recommended setpoint at 2 gallons.

Low-low level alarm is a misnomer. It does not indicate an alarm condition. No response is required from the operator other than to acknowledge the alarm. Its function is a part of normal operations in that it shuts off the sump pump(s) in the automatic mode.

4.2.4.1 Setpoint LALL_RRSUMP: The set point is defined by the following criteria:

- Drain the sump to the maximum extent, but still provide enough residual liquid to maintain pump prime. [Running the pump dry against the head pressure of the residual liquid in the discharge line can compress the air inside the pump to the extent that it loses its suction. Minimizing the dry pump time will help ensure that the pump maintains its prime.]

\subsection{HVAC SUMP}

The HVAC sump has a volume of 94 gallons. At 30 psi pressure, one pump will drain the sump at a rate of $18 \mathrm{gpm}$. Therefore it takes approximately 5.2 minutes to drain the sump. The sump level indicator is LIC-04 which ranges from 1 to 94 gallons. The pump starts at high level and shuts off at low level. The sparger starts at high level and shuts off at low level. Alarms occur for sump levels high-high, high, and low. An alarm is also set for a leak through the sump liner. The alarm setpoint recommendations are given below. 
4.3.1 High-high level alarm LAHH-04: Recommended setpoint at 60 gallons. This alarm notifies the operator that the sump pump did not start. It indicates that:

- The sump pump is not operating. [Most probable scenario. Likely causes include Emergency Stop button not reset; computer did not respond to high level indication; and/or computer did not reset start button on previous low level indication.]

- And/or the fill rate from the ACT-2 condensate line exceeds the pump discharge rate. [Unlikely scenario. Likely causes include a restriction in the pump discharge line and/or plugged suction line.]

\subsubsection{Recommended alarm response:}

- $\quad$ Sump pump not operating: The pump would typically be in automatic mode. When the alarm is received the operator should look at his computer screen to determine if the icon is blue or white. If it is blue, the pump probably did not start. The operator should verify that the pump auto/manual switch is in auto position and push the emergency reset button. If the icon is still blue, the operator should place the auto/manual switch in manual position and push the manual start switch. If the icon is still blue, operations will need to evaluate whether the ACT2 system can be shut down without compromising building containment, and consider placing a portable submersible pump in the sump to transfer the contents to the railroad pit.

- $\quad$ Fill rate exceeds discharge rate. Although this is a very unlikely scenario, once the operator has confirmed that the pump did not start, the operator needs to take steps to place a portable pump in to sump and pump the liquids into the railroad pit, and contact maintenance.

4.3.1.2 Setpoint LAHH_HVAC: The setpoint is defined by the following criteria:

- Provide alarm response time, before the sump overflows,

- Maintain separation between the pump start and high-high level alarm to allow the pump to start and get up to speed without activating the high-high level alarm. [Avoids false alarms.]

- The HVAC sump contains two isolation valves. The setpoint ensures that the valves will not be immersed during operation.

The 60 gallon setpoint will satisfy the criteria.

4.3.2 High level alarm LAH-04: Recommended setpoint at 45 gallons.

High level alarm is a misnomer. It does not indicate an alarm condition. No response is required from the operator other than to acknowledge the alarm. Its function is a part of normal operations in that it starts the sump pump in the automatic mode. 
4.3.2.1 Setpoint LAH_HVAC: The setpoint is defined by the following criteria:

- Maximize the volume of liquid in the sump before the pump starts, to reduce start/stop cycling of the pump. (Reduces wear and tear on the machine.]

- Maintain separation between pump start and high-high level alarm to allow the pump to prime and get up to speed without activating the high-high level alarm. [Avoids false alarms.]

Whereas the sump volume is approximately 93 gallons, and the high-high level alarm is set at 60 gallons, starting the pump at 45 gallons will satisfy the criteria.

4.3.3 Low level alarm LAL-04: Recommended setpoint at 2 gallons.

Low level alarm is a misnomer. It does not indicate an alarm condition. No response is required from the operator other than to acknowledge the alarm. Its function is a part of normal operations in that it stops the sump pump(s) in the automatic mode.

4.3.2 Setpoint LAL_HVAC: The set point is defined by the following criteria:

- $\quad$ Ensure that the sump pump does not run in a dry sump. [Pumping in a dry sump accelerates wear and tear on the pump.]

- A 2 gallon setpoint [equivalent to a 1-inch liquid depth in the sump] will ensure that the pump does not run in a dry sump.

\subsection{TANK 220}

Tank 220 has a volume of 15,101 gallons. At 30 psi pressure, one pump will drain the sump at a rate of $120 \mathrm{gpm}$. Therefore it takes approximately 126 minutes to drain the sump. The tank level indicator is LIC-220 which ranges from 286 to 15,054 gallons. The pumping into the tank shuts off at high level. Alarms occur for sump levels high-high, high, and low. The alarm setpoint recommendations are given below.

4.4.1 High-high level alarm LAHH-220: Recommended setpoint at 14,000 gallons.

4.4.1.1 Setpoint LAHH_T220: The setpoint is defined by the following criteria.

- The limit ensures adequate operator response time to prevent a tank overflow.

4.4.2 High level alarm LAH-220: Recommended setpoint at 13,000 gallons [approximately 12 inches below high-high level alarm].

4.4.2.1 Setpoint LAH_T220: The setpoint is defined by the following criteria.

- The limit maintains enough space between the High and High-high level alarms that the tank agitator will not inadvertently activate the High-high level alarm. 


\section{HNF-3945, Rev. 0}

4.4.3 Low level alarm LAL-220: Recommended setpoint at 2,500 gallons

4.4.3.1 Setpoint LAL_T220: The setpoint is defined by the following criteria.

- The low liquid level alarm is used to shut off the agitator while the blades are still immersed in the liquid. The limit ensures that the agitator will not operate with the blades exposed.

\subsection{TANK 221}

Tank 221 has a volume of 6057 gallons. At 30 psi pressure, one pump will drain the sump at a rate of $120 \mathrm{gpm}$. Therefore, it takes approximately 50 minutes to drain the sump. The tank level indicator is T221-LVL which ranges from 165 to 6,057 gallons. The pumping into the tank shuts off at high level. Alarms occur for sump levels high-high, high, and low. The alarm setpoint recommendations are given below.

4.5.1 High-high level alarm LAHH-221: Recommended setpoint at 5,000 gallons.

4.5.1.1 Setpoint LAHH_T221: The setpoint is defined by the following criteria.

- The limit ensures adequate operator response time to prevent a tank overflow.

4.5.2 High level alarm LAH-221: Recommended setpoint at 4,200 gallons.

4.5.2.1 Setpoint LAH_T221: The setpoint is defined by the following criteria.

- The limit maintains enough space between the High and High-high level alarms that the tank agitator will not inadvertently activate the High-high level alarm.

4.5.3 Low level alarm LAL-221: Recommended setpoint at 1,800 gallons

4.5.3.1 Setpoint LAL_T221: The setpoint is defined by the following criteria.

- The low liquid level alarm is used to shut off the agitator while the blades are still immersed in the liquid. The limit ensures that the agitator will not operate with the blades exposed.

\subsection{REFERENCES}

HNF-PRO-440, Engineering Document Change Control Requirements, Fluor Daniel Hanford, Inc., Richland Washington.

HNF-PRO-3940, 2704-T Complex Distributed Control System Software Configuration Management Plan, Fluor Daniel Hanford, Inc., Richland, Washington. 
HNF-3945, Rev. 0

APPENDIX A

DCS TAG and SETPOINT LIST 
HNF-3945, Rev. 0

This page intentionally left blank 
HNF-3945, Rev. 0

\begin{tabular}{|c|}
\hline DR \\
\hline 1. \\
\hline 1 \\
\hline \\
\hline 1. \\
\hline 1 \\
\hline It \\
\hline 1 \\
\hline 1 \\
\hline 1 \\
\hline 1 \\
\hline 1 \\
\hline 1 \\
\hline 1 ? \\
\hline 1. \\
\hline 1 \\
\hline 1 \\
\hline 1 \\
\hline 1 \\
\hline 1 \\
\hline-11 \\
\hline 1 \\
\hline 1 \\
\hline 1 \\
\hline 1 \\
\hline 1 \\
\hline 1 \\
\hline 1 \\
\hline 9 \\
\hline 1 \\
\hline 1 \\
\hline 1 \\
\hline 1 \\
\hline 1 \\
\hline 1 \\
\hline 1) \\
\hline 1 \\
\hline 1 \\
\hline 1 \\
\hline 1 \\
\hline 2 \\
\hline 2 \\
\hline 2 \\
\hline 2 \\
\hline 2 \\
\hline 2 \\
\hline 21 \\
\hline 2 \\
\hline 2 \\
\hline 2 \\
\hline 2 \\
\hline 3 \\
\hline 3 \\
\hline 3 \\
\hline 3 \\
\hline 3 \\
\hline 3 \\
\hline 3 \\
\hline 3 \\
\hline 3 \\
\hline 3 \\
\hline 3] \\
\hline 3 \\
\hline 3 \\
\hline 3 \\
\hline 3 \\
\hline 3 \\
\hline 3 \\
\hline 3 \\
\hline 3 \\
\hline 3 \\
\hline 3 \\
\hline 3 \\
\hline 1 \\
\hline 1 \\
\hline 1 \\
\hline $\bar{i}$ \\
\hline 1 \\
\hline 1 \\
\hline 1 \\
\hline 1 \\
\hline 1 \\
\hline 2 \\
\hline 2 \\
\hline 2 \\
\hline 2 \\
\hline 3 \\
\hline 3 \\
\hline 3 \\
\hline 3 \\
\hline 1 \\
\hline 1 \\
\hline$i$ \\
\hline 2 \\
\hline 3 \\
\hline 3 \\
\hline (1) \\
\hline \\
\hline
\end{tabular}


HNF-3945, Rev. 0

\begin{tabular}{|c|}
\hline \\
\hline 1 \\
\hline 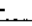 \\
\hline • \\
\hline \\
\hline • \\
\hline \\
\hline \\
\hline \\
\hline 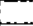 \\
\hline \\
\hline L \\
\hline \\
\hline 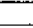 \\
\hline \\
\hline 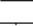 \\
\hline \\
\hline - \\
\hline \\
\hline \\
\hline \\
\hline \\
\hline . \\
\hline \\
\hline \\
\hline \\
\hline \\
\hline \\
\hline \\
\hline \\
\hline \\
\hline • \\
\hline 2 \\
\hline- \\
\hline \\
\hline \\
\hline \\
\hline- \\
\hline 2 \\
\hline - \\
\hline$\overline{1}$ \\
\hline 1 \\
\hline 1 \\
\hline$\overline{1}$ \\
\hline 7 \\
\hline 1 \\
\hline 1 \\
\hline$=$ \\
\hline 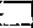 \\
\hline 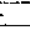 \\
\hline 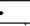 \\
\hline \\
\hline 2 \\
\hline 2 \\
\hline \\
\hline \\
\hline 1 \\
\hline \\
\hline \\
\hline . \\
\hline \\
\hline 2 \\
\hline \\
\hline 1 \\
\hline 1 \\
\hline 3 \\
\hline \\
\hline \\
\hline \\
\hline \\
\hline \\
\hline- \\
\hline \\
\hline 0 \\
\hline 3 \\
\hline \\
\hline \\
\hline \\
\hline \\
\hline \\
\hline \\
\hline \\
\hline \\
\hline \\
\hline \\
\hline \\
\hline 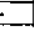 \\
\hline \\
\hline \\
\hline \\
\hline \\
\hline \\
\hline- \\
\hline \\
\hline 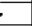 \\
\hline \\
\hline 3 \\
\hline 2 \\
\hline
\end{tabular}


HNF-3945, Rev. 0

\begin{tabular}{|c|c|}
\hline$\frac{2}{2}$ & $\frac{3}{4}$ \\
\hline & \\
\hline & \\
\hline & \\
\hline & \\
\hline & \\
\hline & \\
\hline 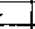 & \\
\hline & \\
\hline & \\
\hline 2 & \\
\hline & \\
\hline & \\
\hline & 4 \\
\hline 1 & 3 \\
\hline 2 & 2 \\
\hline 2 & 21 \\
\hline & \\
\hline & \\
\hline & \\
\hline & \\
\hline 3 & \\
\hline 3 & 2 \\
\hline & \\
\hline & \\
\hline & \\
\hline & \\
\hline & \\
\hline & \\
\hline & \\
\hline & \\
\hline & \\
\hline & \\
\hline & \\
\hline & \\
\hline & \\
\hline & \\
\hline & \\
\hline & \\
\hline 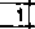 & \\
\hline & \\
\hline & 2 \\
\hline 3 & 22 \\
\hline & \\
\hline 1 & 5 \\
\hline 1 & 5 \\
\hline 1 & 51 \\
\hline & \\
\hline & \\
\hline & \\
\hline & \\
\hline & \\
\hline & \\
\hline & \\
\hline & \\
\hline & \\
\hline & \\
\hline & \\
\hline 7 & \\
\hline$\square$ & \\
\hline & \\
\hline & \\
\hline & \\
\hline & \\
\hline & \\
\hline & \\
\hline & \\
\hline & \\
\hline & \\
\hline 3 & \\
\hline & \\
\hline & \\
\hline & \\
\hline & . \\
\hline - & \\
\hline & \\
\hline 1 & $4 \sqrt{3}$ \\
\hline & $4 / 2$ \\
\hline & $4 \sqrt[3]{3}$ \\
\hline 1 . & $4 \sqrt[3]{3}$ \\
\hline 1 & \\
\hline & \\
\hline & \\
\hline 2 & 3. \\
\hline & \\
\hline & $\div$ \\
\hline & \\
\hline & 10 \\
\hline 4 & \\
\hline & \\
\hline & \\
\hline 2 & \\
\hline & \\
\hline 3$]$ & \\
\hline & \\
\hline 1) & 5 \\
\hline $1:$ & $5 \longdiv { 2 }$ \\
\hline
\end{tabular}


HNF-3945, Rev. 0

\begin{tabular}{|c|}
\hline . \\
\hline \\
\hline \\
\hline - \\
\hline \\
\hline \\
\hline- \\
\hline$\theta$ \\
\hline \\
\hline 1 \\
\hline- \\
\hline$\theta$ \\
\hline \\
\hline$=$ \\
\hline$\because$ \\
\hline$\theta$ \\
\hline \\
\hline 1 \\
\hline 3 \\
\hline 3 \\
\hline- \\
\hline- \\
\hline 7 \\
\hline \\
\hline 2 \\
\hline \\
\hline \\
\hline \\
\hline \\
\hline \\
\hline- \\
\hline \\
\hline- \\
\hline$=$ \\
\hline \\
\hline$\cdot$ \\
\hline . \\
\hline \\
\hline 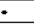 \\
\hline 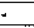 \\
\hline \\
\hline$\therefore$ \\
\hline- \\
\hline \\
\hline - \\
\hline$\because$ \\
\hline \\
\hline 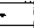 \\
\hline 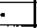 \\
\hline \\
\hline • \\
\hline • \\
\hline \\
\hline \\
\hline 1 \\
\hline 3 \\
\hline 3 \\
\hline 3 \\
\hline 3 \\
\hline 1 \\
\hline 1 \\
\hline 3 \\
\hline 3 \\
\hline 3 \\
\hline 3 \\
\hline 3 \\
\hline 1 \\
\hline i) \\
\hline 1 \\
\hline 11 \\
\hline 2 \\
\hline 2 \\
\hline 2 \\
\hline 2 \\
\hline 2 \\
\hline 1 \\
\hline 1 \\
\hline 3 \\
\hline 3 \\
\hline 3 \\
\hline 3 \\
\hline 3 \\
\hline 3 \\
\hline 3. \\
\hline 1 \\
\hline 1 \\
\hline 1 \\
\hline 1 \\
\hline 2 \\
\hline 2 \\
\hline 2 \\
\hline 2 \\
\hline 2 \\
\hline 1 \\
\hline 1 \\
\hline 3 \\
\hline 3 \\
\hline \\
\hline
\end{tabular}


HNF-3945, Rev. 0

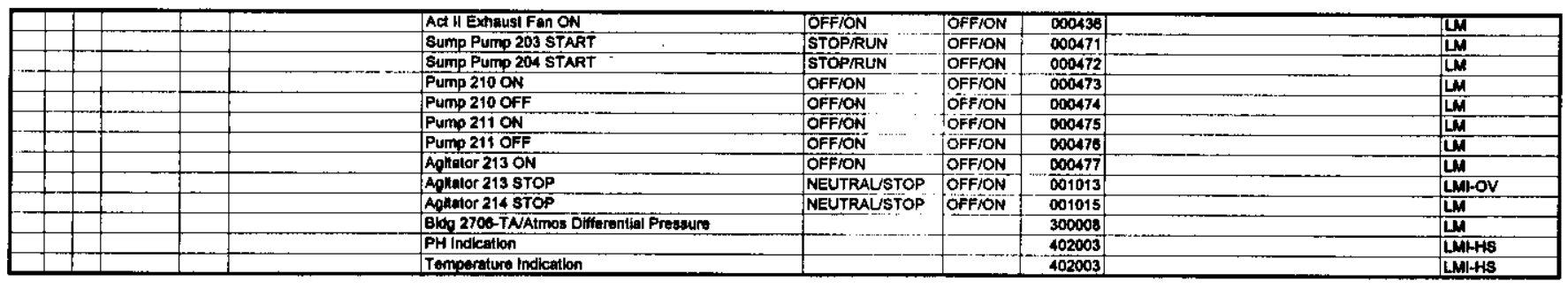

